\title{
Competence of mosquitoes native to the United Kingdom to support replication and transmission of Rift Valley fever virus
}

Sarah Lumley ${ }^{1,2,3^{*}}$ (D), Luis M. Hernández-Triana ${ }^{3}$, Daniel L. Horton², Maria Del Mar Fernández de Marco3, Jolyon M. Medlock', Roger Hewson 1,4, Anthony R. Fooks $3,4,5$ and Nicholas Johnson ${ }^{2,3}$

\begin{abstract}
Background: Rift Valley fever phlebovirus (RVFV) is a mosquito-borne arbovirus causing severe disease in humans and livestock. It is endemic in Africa and spread to the Arabian Peninsula in 2000 raising concerns it could emerge in Europe. The ability of temperate mosquitoes from the United Kingdom (UK) to support replication and transmission of RVFV is unknown.

Methods: In this study, two colonised lines of Culex pipiens, wild-caught Aedes detritus and Ae. rusticus from the UK were infected with pathogenic strains of RVFV to assess their vector competence. Mosquitoes were offered artificial blood-meals containing $10^{6}$ or $10^{7}$ plaque forming units (PFU)/ml RVFV, simulating natural peak viraemia in young ruminants, and maintained at $20^{\circ} \mathrm{C}$ or $25^{\circ} \mathrm{C}$ for up to 21 days. Bodies, legs and saliva were collected and tested for the presence of viral RNA and infectious virus to determine the infection, dissemination and transmission potential.

Results: Across temperatures, doses and strains the average infection, dissemination and transmission rates were: 35, 13 and 5\% ( $n=91)$ for Cx. pipiens (Caldbeck); 23, 14 and 5\% ( $n=138)$ for CX. pipiens (Brookwood); 36, 28 and $7 \%(n=118)$ for Ae. detritus. However, despite 35\% ( $n=20)$ being susceptible to infection, Ae. rusticus did not transmit RVFV. Survival of Aedes species was negatively affected by maintenance at $25^{\circ} \mathrm{C}$ compared to the more representative peak average British summer temperature of $20^{\circ} \mathrm{C}$. Increased mortality was also observed with some species infected with $10^{7} \mathrm{PFU} / \mathrm{ml}$ compared to $10^{6} \mathrm{PFU} / \mathrm{ml}$.
\end{abstract}

Conclusions: It can be concluded that temperate mosquito species present in the UK demonstrate a transmission potential for RVFV in the laboratory but, even at high temperatures, this occurred at low efficiency.

Keywords: Rift Valley fever virus, Mosquito, Vector competence, UK, Arbovirus

\section{Background}

Rift Valley fever phlebovirus (RVFV; Phenuiviridae) is a pathogen of both veterinary and public health importance: causing abortions and mortality in ruminants and disease ranging from febrile illness to encephalitis and haemorrhagic fever in humans [1,2]. Endemic throughout Africa RVFV was introduced into the Arabian Peninsula in 2000 [3] providing evidence that it could emerge in new regions. The detection of RVFV specific antibodies in ruminants in Turkey [4], further raises

\footnotetext{
*Correspondence: sarah.lumley@phe.gov.uk

${ }^{1}$ Microbiology Services Division, Public Health England, Wiltshire, UK

${ }^{2} \mathrm{~S} c h \mathrm{col}$ of Veterinary Medicine, University of Surrey, Guildford, UK

Full list of author information is available at the end of the article
}

concerns that RVFV could emerge in Europe. The virus is maintained in a transmission cycle between mosquito and mammalian hosts. It infects a broad range of mainly tropical mosquito species predominantly within the genera Aedes and Culex, with detection in over 50 species in the wild and 47 vector-competent species in laboratory studies (reviewed in [5]).

The potential pathways for RVFV introduction into Europe have been identified [6]. However, there is limited information on the ability of temperate mosquito species to transmit RVFV. In endemic regions, floodwater Aedes spp. are considered maintenance vectors of RVFV. There is evidence to suggest RVFV can pass transovarially from infected female mosquitoes to their

(C) The Author(s). 2018 Open Access This article is distributed under the terms of the Creative Commons Attribution 4.0 International License (http://creativecommons.org/licenses/by/4.0/), which permits unrestricted use, distribution, and 
progeny [5, 7]. This has led to competing hypotheses that RVFV survives long inter-epizootic periods within desiccated eggs of Aedinae species $[5,7]$ or remains active in wildlife populations undetected by human surveillance [8]. After prolonged periods of rainfall huge numbers of adult mosquitoes emerge, of which a small percentage are thought to be infected (reviewed by Lumley et al. [5]). The expansion of the mosquito population is thought to then drive outbreaks of RVF [7, 9].

Culex species are considered amplifying vectors during epizootics, spreading RVFV to humans and ruminants. The northern house mosquito, Culex pipiens, was the principal vector in the epizootic in Egypt 1977 [2, 10]. This species exists in two morphologically identical forms biotype pipiens and molestus, and a hybrid of the two [11]. The main vector in the Egyptian epizootic was likely the molestus form [11] but was not distinguished from another member of the complex, $C x$. quinquefasciatus (southern house mosquito). Culex quinquefasciatus occupies tropical regions overlapping with $C x$. pipiens in central/northern Africa and South Africa [12]. Historically biotypes were not distinguished but differential patterns of vector competence occur between both biotypes and hybrids, demonstrated in the Netherlands, USA and Spain [13-15].

There have been 36 mosquito species reported in the UK [16] of which 15 are Aedinae and 4 Culex. Based on records of abundance and feeding preference the following have potential as RVFV vectors: Ae. annulipes, Ae. cantans, Ae. caspius, Ae cinereus/geminus, Ae detritus,
Ae. punctor and Ae. rusticus [17, 18]. The four Culex species in the UK are $C x$. europaeus, $C x$. modestus, $C x$. pipiens and $C x$. torrentium. The Culex pipiens $\mathrm{f}$. pipiens feeds preferentially on birds and infrequently on humans, whilst the molestus biotype feeds readily on humans. The hybrid is considered to exhibit intermediary behaviours [11]. Reports of Cx. pipiens $\mathrm{f}$. pipiens biting humans and livestock are rare. However, an understanding of the ability of Cx. pipiens (sensu lato) in the UK to transmit RVFV is of relevance due to its abundance, proximity to humans and livestock, homology to known vectors in Africa and the co-occurrence of biotypes and hybrids. To improve our understanding of the ability of temperate mosquito species to transmit RVFV, the vector competence of four mosquito populations derived from the UK were evaluated.

\section{Methods}

\section{Source of mosquitoes}

Mosquitoes used are listed in Table 1, including collection location, habitat and filial generation. A map of collection sites is presented in Additional file 1: Figure S1. Species were identified using published keys $[19,20]$ and a polymerase chain reaction (PCR) targeting mitochondrial cytochrome $c$ oxidase subunit 1 (cox1) gene [21]. Four Aedes species were collected from two diverse habitat types during 2016 and 2017. Aedes rusticus and Ae. cantans/annulipes were collected from woodland frequented by humans and inhabited by deer and cattle. Aedes detritus and Ae. caspius were collected from two

Table 1 Provenance of mosquitoes used in Rift Valley fever virus vector competence studies

\begin{tabular}{|c|c|c|c|c|c|c|}
\hline Species (shorthand) & Location (Reference) & GPS coordinates (DMS) & Origin & Generation & Collection method & Habitat \\
\hline $\begin{array}{l}\text { Cx. pipiens Caldbeck } \\
\text { (CBK) }\end{array}$ & $\begin{array}{l}\text { Caldbeck, Worcester } \\
\text { Park, London }\end{array}$ & $\begin{array}{l}51^{\circ} 22^{\prime} 51.24^{\prime \prime} \mathrm{N}, 0^{\circ} \\
14^{\prime} 20.399^{\prime \prime} \mathrm{W}\end{array}$ & $\begin{array}{l}\text { Larvae, pupae } \\
\text { (colonised) }\end{array}$ & $>\mathrm{F} 100^{\mathrm{a}}$ & $c$ & $\begin{array}{l}\text { Freshwater pond/ } \\
\text { drainage ditch }\end{array}$ \\
\hline $\begin{array}{l}\text { Cx.pipiens Brookwood } \\
\text { (BKW) }\end{array}$ & Brookwood, Surrey & $\begin{array}{l}51^{\circ} 18^{\prime} 23.4^{\prime \prime} \mathrm{N}, 0^{\circ} \\
37^{\prime} 58.08^{\prime \prime} \mathrm{W}\end{array}$ & $\begin{array}{l}\text { Larvae, pupae } \\
\text { (colonised) }\end{array}$ & $>\mathrm{F} 100^{\mathrm{b}}$ & c & Container \\
\hline $\begin{array}{l}\text { Cx. pipiens (sensu lato), } \\
\text { Cx. modestus }\end{array}$ & Cliffe Pools, Kent & $\begin{array}{l}51^{\circ} 28^{\prime} 21.032^{\prime \prime} \mathrm{N}, 0^{\circ} \\
28^{\prime} 31.575^{\prime \prime} \mathrm{E}\end{array}$ & Larvae, pupae & Fo & Dipping & $\begin{array}{l}\text { Freshwater pond/ } \\
\text { drainage ditch }\end{array}$ \\
\hline $\begin{array}{l}\text { Cx. pipiens (s.l.), } C X \text {. } \\
\text { modestus }\end{array}$ & $\begin{array}{l}\text { Elmley National Nature } \\
\text { Reserve, Kent }\end{array}$ & $\begin{array}{l}51^{\circ} 22^{\prime} 59.288^{\prime \prime} \mathrm{N}, 0^{\circ} \\
46^{\prime} 57.459^{\prime \prime} \mathrm{E}\end{array}$ & Larvae, pupae & FO & Dipping & $\begin{array}{l}\text { Freshwater pond/ } \\
\text { drainage ditch }\end{array}$ \\
\hline Cx. pipiens (s.l.) & West Byfleet, Surrey & $\begin{array}{l}51^{\circ} 20^{\prime} 35.084^{\prime \prime} \mathrm{N}, 0^{\circ} \\
29^{\prime} 56.664^{\prime \prime} \mathrm{W}\end{array}$ & Eggs & F0 & Dipping & Container \\
\hline Ae. detritus, Ae. caspius & Wallasea Island, Essex & $\begin{array}{l}51^{\circ} 36^{\prime} 55.065^{\prime \prime} \mathrm{N}, 0^{\circ} \\
49^{\prime} 22.066^{\prime \prime} \mathrm{E}\end{array}$ & Adults & F0 & $\mathrm{CO}_{2}$ traps & Saltmarsh \\
\hline $\begin{array}{l}\text { Ae. rusticus, Ae. cantans/ } \\
\text { Ae. annulipes }\end{array}$ & $\begin{array}{l}\text { Bartley Heath, } \\
\text { Hampshire }\end{array}$ & $\begin{array}{l}51^{\circ} 16^{\prime} 32.568^{\prime \prime} \mathrm{N}, 0^{\circ} \\
57^{\prime} 18.207^{\prime} \mathrm{W}\end{array}$ & Adults & F0 & Human landing & $\begin{array}{l}\text { Woodland/temporary } \\
\text { groundwater }\end{array}$ \\
\hline Ae. detritus & Dee Marsh, Cheshire & $\begin{array}{l}53^{\circ} 16^{\prime} 39.48^{\prime \prime} \mathrm{N}, 3^{\circ} \\
4^{\prime} 5.286 " \mathrm{~W}\end{array}$ & Larvae, pupae & FO & Dipping & Saltmarsh \\
\hline
\end{tabular}

${ }^{\mathrm{a}}$ The Caldbeck colony was established from filial generation f50 at APHA in February 2015

${ }^{\mathrm{b}}$ The Brookwood colony f51 in February 2016

'Collected, colonised and characterised by the Pirbright Institute [22]

Dipping refers to the use of pans to collect larvae using a scooping action to target collection of Aedes spp. or a tilting action allowing the passive flow of water into the pan to target Culex larvae as described previously [50]. The females of Ae. cantans and Ae. annulipes cannot be reliably identified based on morphological traits [51]. Our attempts to molecularly confirm the identity of specimens from Bartley Heath by using the DNA barcoding retrieved ambiguous results for the species; therefore, we treat Ae. cantans/Ae. annulipes in our dataset. Locations are based on survey sites from [22, 52-54], a map of locations is presented in Additional file 1: Figure S1 
coastal areas with frequent reports of nuisance biting. Two colonised lines within the Culex pipiens complex were maintained, previously characterised as a $C x$. pipiens f. pipiens (Caldbeck: CBK) and Cx. pipiens/ molestus hybrid (Brookwood: BKW) (donated by the Pirbright Institute, UK) [22]. Colonised larvae were reared at $22.5 \pm 3.5^{\circ} \mathrm{C}$ in filtered water and wild-caught juveniles reared at $20 \pm 1.5^{\circ} \mathrm{C}$ ) in collection site water. Both were fed fish flake (Aquarian, Grantham, UK). Colonised adults were maintained at $25 \pm 2.7^{\circ} \mathrm{C}$ and wild-caught at $20 \pm 2.5^{\circ} \mathrm{C}$ ). Both were maintained on cotton wool saturated in $10 \%$ sucrose, with a photoperiod of 12:12 (light: dark) hours. Colonised mosquitoes were blood-fed twice a week on defibrinated horse blood (TCS Biosciences, Buckingham, UK) by hemotek with a parafilm (Sigma-Aldrich, Gillingham, UK) membrane. Black cups were supplied containing filtered water for oviposition and eggs collected and transferred to rearing trays twice a week.

RVFV strains used to assess vector competence

All manipulations of samples known or suspected to contain infectious RVFV were performed within Biosafety level 3 (BSL-3) laboratories. Two strains of RVFV were used: ZH501 (mouse brain suspension; passage 10) isolated from a fatal human haemorrhagic case in Egypt 1977 [10] and Lunyo (mouse brain suspension; passage 11) isolated in 1953 from Aedes mosquitoes in the Lunyo Forest, Uganda [23, 24]. Strain ZH501 was selected as it is a well characterised strain used in over 30 previous studies of vector competence (reviewed by Lumley et al. [5]), the second strain Lunyo was selected to permit comparison to a divergent strain from a different clade [25] with $96.4 \%$ homology to ZH501 at the nucleotide level. Virus was propagated on Vero E6 cells at $37{ }^{\circ} \mathrm{C}$ for 3 days and quantified by quantitative reverse transcription (qRT)-PCR and plaque assay. Virus was concentrated for use at the higher titre (to account for dilution during blood meal preparation) using $100 \mathrm{kDa}$ AmiconUltra-15 centrifugal filter devices (Merck Millipore, Feltham, UK) at $3,800 \times g$ for $40 \mathrm{~min}$ at $4{ }^{\circ} \mathrm{C}$ following manufacturer's instructions and adapted from [26]. Stocks were stored at $-80{ }^{\circ} \mathrm{C}$.

\section{Evaluating vector competence}

Mosquitoes were offered blood-meals containing either RVFV strain at two doses: $10^{6}$ and $10^{7}$ plaque forming units $(\mathrm{PFU}) / \mathrm{ml}$ which fall within the natural livestock viraemia [27, 28]. A typical viraemia profile for a susceptible vertebrate species previously demonstrating support of onward transmission to vectors is shown in Fig. 1a [28]. Prior to feeding, sucrose was removed and mosquitoes were maintained on water for 16-22 h and starved of water for the last three hours. Mosquitoes (510 days-old) were fed through a Parafilm M (Sigma) membrane overnight (15-18 h) in a darkened BugDorm (Bugzarre, Lowestoft, UK), using a hemotek (Hemotek Ltd., Blackburn, UK) set at $37{ }^{\circ} \mathrm{C}$. Infectious RVFV is reported to be highly stable in proteinaceous mediums, preliminary experiments (data not shown) demonstrated a less than one log reduction in infectious RVFV titre in blood maintained at $37{ }^{\circ} \mathrm{C}$ for $24 \mathrm{~h}$ simulating an artificial blood meal (reviewed by EFSA [29]). The blood meal was prepared using defibrinated horse blood (TCS Biosciences), $1 \mu \mathrm{M}$ dATP (final concentration) (Thermo Fisher Scientific, Warrington, UK) and RVFV at a ratio of 1:2 (virus: blood). Control blood was prepared substituting virus for Dulbecco's modified Eagle medium (DMEM) (Thermo Fisher Scientific). Blood-meal samples were taken before and after feeding and stored at $-80{ }^{\circ} \mathrm{C}$ for quantification.

Post-feeding, mosquitoes were anaesthetised using FlyNap (Carolina Biological Supply, Burlington, US) and engorged mosquitoes sorted into groups of 10-15 in to $73 \times 118 \mathrm{~mm}$ microhabitat pots with a mesh vent (Bugzarre). Mosquitoes were sampled on day 0 to calculate the dose ingested. Mosquitoes were maintained at 20 or $25{ }^{\circ} \mathrm{C}$ on water-soaked cotton and filter paper discs saturated in mānuka honey. Survival was monitored periodically and water replaced as required. Honey-filters were collected every 24-72 h from day 7 onwards and stored at $-80{ }^{\circ} \mathrm{C}$. At designated collection points, 7, 14 and 21 days post-infection (dpi), mosquitoes were anaesthetised with FlyNap. Legs and wings were collected, to assess virus dissemination, into $2 \mathrm{ml}$ tubes containing $14 \mathrm{~mm}$ ceramic beads (Stretton Scientific, Stretton, UK) and $300 \mu \mathrm{l}$ mosquito buffer (Eagle's minimum essential medium supplemented with $20 \%$ FBS and 100 units $/ \mathrm{ml}$ penicillin, $100 \mu \mathrm{g} / \mathrm{ml}$ streptomycin, $0.25 \mu \mathrm{g} / \mathrm{ml}$ amphotericin B) (Sigma-Aldrich). Saliva was collected to assess virus transmission [30]. The proboscis was inserted into a trimmed $200 \mu \mathrm{l}$ micropipette tip containing $20 \mu \mathrm{l}$ mosquito buffer supplemented with $50 \%$ sucrose. Five microlitres of pilocarpine mix was applied to the abdomen to encourage salivation $[1 \%$ pilocarpine hydrochlorides (Thermo Fisher Scientific), 0.1\% Tween 80 in PBS (Sigma-Aldrich)] and after 30-45 minutes media containing expectorated saliva was expelled into $280 \mu \mathrm{l}$ mosquito buffer. To reduce PCR inhibition mosquitoes were decapitated [31] and the body (abdomen and thorax) collected and stored as were the legs. Body and legs were disrupted by two $20 \mathrm{~s}$ cycles of $4500 \times \mathrm{rpm}$ with a $30 \mathrm{~s}$ mid-cycle pause on the Precellys 24 homogeniser (Stretton Scientific). All samples were centrifuged at $3000 \times g$ for $10 \mathrm{~min}$ and processed in the first instance for virus by qRT-PCR. The remaining sample was stored at $-80{ }^{\circ} \mathrm{C}$ and plaque assays were performed on positive samples only. 
a

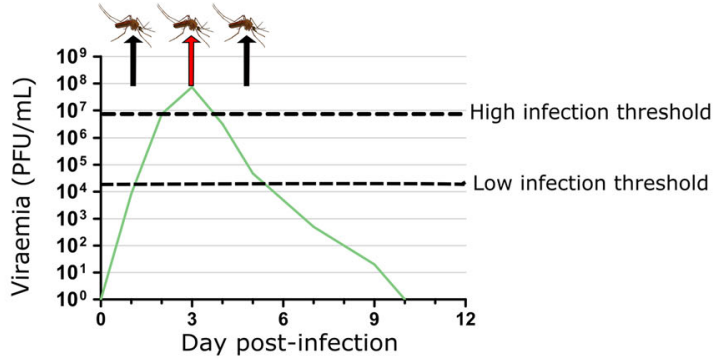

b

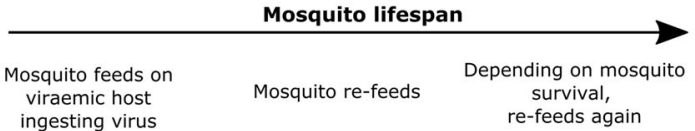

Scenario 1.

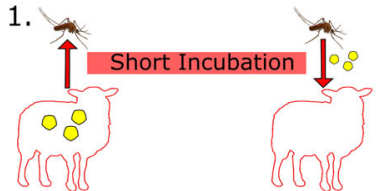

Scenario 2.
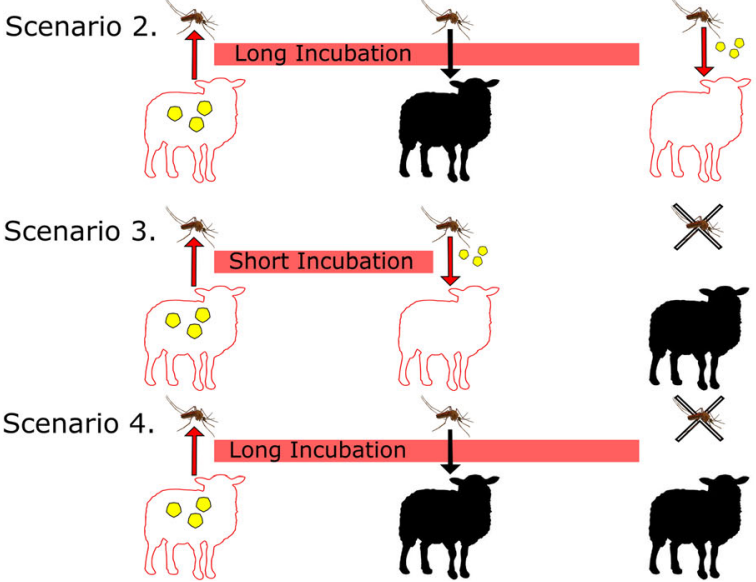

Fig. 1 Timeline of events effecting mosquito viral transmission. a Schematic of a typical livestock viraemia profile based on experimental infection of ruminants reviewed by Golnar et al. [28]. Viraemia is affected by both age and species of the host, dose, strain and route of inoculum [1], the schematic is therefore representative not absolute. Dotted lines represent a high threshold set by Golnar et al. [28] and a low dose threshold required to infect mosquitoes based on the findings of Vloet et al. [44], the latter facilitates onward infection of the mosquito across a longer duration than the high infectious dose [1]. $\mathbf{b}$ Interplay of the extrinsic incubation period (EIP) and mosquito lifespan on transmission. The EIP is the time from virus ingestion to the first point the mosquito is capable of expectorating virus via its saliva during feeding. The shorter the EIP and longer the lifespan the higher the potential for transmission events to occur, both are affected by multiple factors including environment and species specific traits. Scenario 1: short EIP but long lifespan is optimal for a transmission event; Scenario 2: long EIP with a long lifespan; Scenario 3: short EIP with a short lifespan; Scenario 4: long EIP coupled with short a lifespan does not support transmission. Arrows represent a feeding event, with the arrowhead indicating the direction of virus transmission. Red arrows and red sheep: events support transmission; black arrows and black sheep: events do not support transmission

\section{Virus detection and quantification}

Viral RNA was extracted using the QIAamp viral RNA mini kit (Qiagen, Manchester, UK) or TRIzol LS kit (Thermo Fisher Scientific) in accordance with the manufacturer's instructions and eluted in $60 \mu \mathrm{l}$. Honey-filters were placed directly into lysis buffer and extracted in parallel with other sample types. Published qRT-PCRs targeting the $\mathrm{M}$ and $\mathrm{S}$ segments $[32,33]$ were performed on the Viia 7 real-time PCR system (Thermo Fisher Scientific), using reaction and cycling parameters recommended for the TaqMan Fast Virus 1-step master mix
(Thermo Fisher Scientific) with $5 \mu$ l template, analysed at baseline 0.05. Genome equivalent copies (GEC) were calculated using the molecular weight and sequence length of a synthetic transcript (GeneArt, Thermo Fisher Scientific). To confirm samples were correctly collected and extracted, published endogenous internal controls were employed targeting host actin for the body and leg samples [34] and mitochondria for saliva samples (an additional reverse primer was designed detailed in Additional file 2: Methods S1) [35]. Samples testing negative for host DNA were removed from the population 
number for calculations. However, the advent of the saliva host endogenous control PCR came after the $10^{6}$ PFU dose group experiments were performed and samples were not available to retrospectively test.

Plaque assays were performed on Vero E6 cells (European Collection of Authenticated Cell Cultures), $50 \mu \mathrm{l}$ of virus dilution was adsorbed for 1 hour at $37{ }^{\circ} \mathrm{C}$. An avicel (Sigma-Aldrich) overlay ( $0.5 \mathrm{ml} 0.6 \%$ avicel in MEM) was applied and incubated for 3 days at $37{ }^{\circ} \mathrm{C}$ with $5 \%$ $\mathrm{CO}_{2}$. Overlay for mosquito samples was supplemented with $100 \mathrm{units} / \mathrm{ml}$ penicillin, $100 \mu \mathrm{g} / \mathrm{ml}$ streptomycin, 0 . $25 \mu \mathrm{g} / \mathrm{ml}$ amphotericin B, $100 \mu \mathrm{g} / \mathrm{ml}$ kanamycin, $50 \mu \mathrm{g} /$ $\mathrm{ml}$ gentamicin (Sigma). Cells were fixed and virus inactivated in $10 \%$ formaldehyde for $1 \mathrm{~h}$, and stained with 0 . $2 \%$ crystal violet.

\section{Experimental design}

A summary of the experiments performed are shown in Table 2. Colonised mosquitoes were assessed for their competence for RVFV at a constant temperature of $25^{\circ}$ $\mathrm{C}$, corresponding to their routine rearing and maintenance temperature. Wild-caught species were challenged at $25{ }^{\circ} \mathrm{C}$ for consistency with colony experiments, and where numbers permitted mosquitoes were also challenged at $20{ }^{\circ} \mathrm{C}$ representing peak average temperatures recorded during summer months at larvae collection sites (recorded 1981-2010 by [36]).

\section{Statistical analyses}

Infection, dissemination and transmission rates were calculated as the percentage of blood feeding mosquitoes that survived until a collection point (and positive for endogenous PCR), containing virus in their bodies, legs and saliva, respectively. Sample numbers were guided by the herd sensitivity model for an infinite population size, signifying a sample size requirement of 29 to detect a single positive specimen from a population with $10 \%$ transmission capability with 95\% confidence [37]. Doses and virus strains were compared by Fisher's exact test, using significance threshold 0.05 with Bonferroni-corrected thresholds for multiple comparisons. 95\% confidence intervals $(95 \%$ CI) were calculated by a modified Wald method [38]. Titres were compared using Mann-Whitney or KruskalWallis tests followed by Dunn's post-hoc tests for multiple comparisons. Survival was analysed by a Kaplan-Meier plot (GraphPad Prism), mosquitoes processed for virus detection were censored and groups compared by LogRank test.

\section{Results}

\section{Mosquito survival}

The effects of temperature, RVFV strain and dose on mosquito survival were investigated. Results in Fig. 2a show that Ae. detritus survival was significantly reduced at $25^{\circ} \mathrm{C}$ under experimental conditions compared to $20{ }^{\circ} \mathrm{C}$ when monitored over 14 days (Log-rank (Mantel-Cox) test: $X^{2}=$ 38.06, $d f=1, P<0.0001)$. Results for both RVFV strains and controls were combined (Fig. 2a) as the effect of temperature on survival at $25{ }^{\circ} \mathrm{C}$ compared to $20{ }^{\circ} \mathrm{C}$ appeared independent of virus infection. Significantly more Ae. detritus mosquito survived when infected with $10^{6}$ PFU/ml ZH501 (Log-rank (Mantel-Cox) test: $\chi^{2}=12.28$, $d f=1, P=0.0005)$, Lunyo $\left(\chi^{2}=14.03, d f=1, P=0.0002\right)$ and the uninfected controls $\left(\chi^{2}=6.042, d f=1, P=0.0140\right)$. Repetitions of experiments using $10^{7} \mathrm{PFU} / \mathrm{ml}$ were therefore performed at $20{ }^{\circ} \mathrm{C}$ to promote survival and increase experimental numbers to evaluate competency. Reduced survival at $25{ }^{\circ} \mathrm{C}$ was also observed with $\mathrm{Ae}$. rusticus; however sample numbers were too small to perform statistical analysis with just 2 of 20 surviving until $7 \mathrm{dpi}$.

The effect of RVFV strain on mosquitoes at equivalent doses and temperatures, did not differ significantly between strains (Fig. 2b-d). It was observed that when a higher dose of virus was ingested, mortality increased. A significant increase in Ae. detritus mortality was observed

Table 2 Summary of vector competence experiments performed. The infectious viral titres within the blood meal offered to mosquitoes are written in plaque forming units/ml (PFU)

\begin{tabular}{|c|c|c|c|c|c|c|}
\hline \multirow[t]{2}{*}{ Mosquito species } & \multicolumn{4}{|c|}{$10^{6} \mathrm{PFU}$} & \multicolumn{2}{|c|}{$10^{7} \mathrm{PFU}$} \\
\hline & $\mathrm{ZH} 501$ & & Lunyo & & $\overline{\mathrm{ZH} 501}$ & Lunyo \\
\hline \multirow[t]{2}{*}{ Cx. pipiens (Caldbeck colony) } & $\checkmark$ & & - & & $\checkmark$ & - \\
\hline & $25^{\circ} \mathrm{C}$ & & & & $25^{\circ} \mathrm{C}$ & \\
\hline \multirow[t]{2}{*}{ Cx. pipiens (Brookwood colony) } & - & & $\checkmark$ & & $\checkmark$ & $\checkmark$ \\
\hline & & & $25^{\circ} \mathrm{C}$ & & $25^{\circ} \mathrm{C}$ & $25^{\circ} \mathrm{C}$ \\
\hline \multirow[t]{2}{*}{ Ae. detritus (Wild-caught) } & $\checkmark$ & & $\checkmark$ & & $\checkmark$ & $\checkmark$ \\
\hline & $20^{\circ} \mathrm{C}$ & $25^{\circ} \mathrm{C}$ & $20^{\circ} \mathrm{C}$ & $25^{\circ} \mathrm{C}$ & $20^{\circ} \mathrm{C}$ & $20^{\circ} \mathrm{C}$ \\
\hline \multirow[t]{2}{*}{ Ae. rusticus (Wild-caught) } & $\checkmark$ & & - & & $\checkmark$ & - \\
\hline & $25^{\circ} \mathrm{C}$ & & & & $20^{\circ} \mathrm{C}$ & \\
\hline
\end{tabular}

$\checkmark$ Vector competence experiment was performed under the conditions listed with the incubation temperature written below 


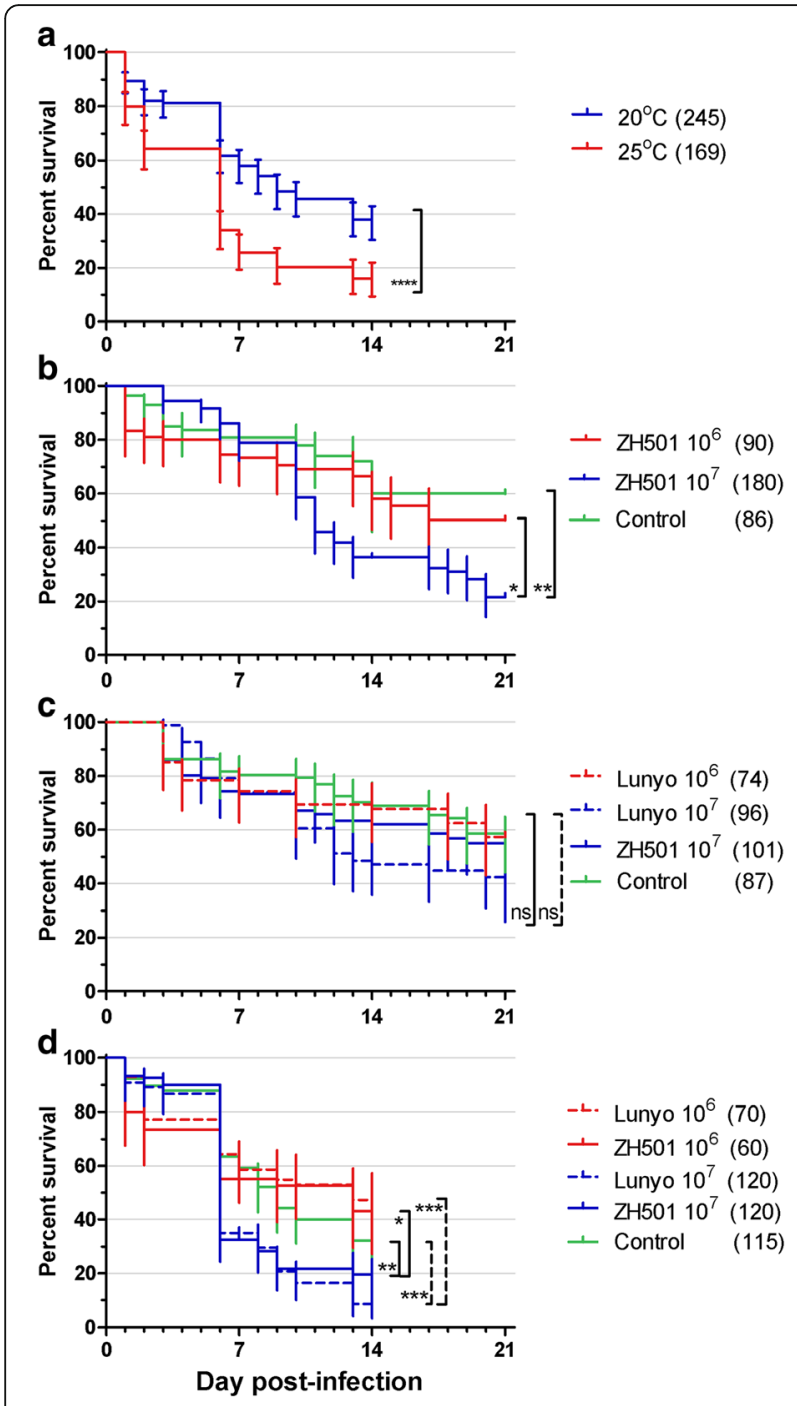

Fig. 2 Percentage survival of mosquitoes. a Effect of temperature on Ae. detritus survival. Mosquitos ingesting a blood meal containing at $10^{6} \mathrm{PFU} /$ $\mathrm{mL}$ RVFV strain ZH501, Lunyo or an uninfected control were maintained at 20 or $25^{\circ} \mathrm{C}$. Survival did not differ statistically between strains or controls at $20^{\circ} \mathrm{C}$ (Log-rank (Mantel-Cox) $X^{2}=1.174, d f=2$,

$P=0.5560)$ or at $25^{\circ} \mathrm{C}\left(x^{2}=0.9600, d f=2, P=0.9600\right)$ so datasets were pooled for analysis, demonstrating reduced survival at $25^{\circ} \mathrm{C}$ compared to $20^{\circ} \mathrm{C}$. The effects of viral dose on survival are presented in panels $\mathbf{b}-\mathbf{d}$ comparing $10^{6} \mathrm{PFU} / \mathrm{ml}$ vs $10^{7} \mathrm{PFU} / \mathrm{ml}$ vs uninfected controls. $\mathbf{b}$ Cx. pipiens f. pipiens (Caldbeck). c Cx. pipiens hybrid (Brookwood). d Ae. detritus. Survival was monitored periodically for up to 21 days. Kaplan-Meier plots were generated in GraphPad Prism, bars represent the 95\% confidence interval, the numbers tested are written within parentheses (n). Statistical differences were calculated by Log-Rank test with Bonferroni-corrected thresholds, dotted lines compare strain: Lunyo, solid lines: ZH501. Demonstrating reduced survival for $C x$. pipiens Caldbeck and Ae. detritus after ingestion of blood containing $10^{7} \mathrm{PFU} / \mathrm{ml}$ compared to controls and their lower dose counterparts but no differences between doses or controls ingested by the Brookwood line mosquitoes

following infection with both RVFV strains (Log-rank (Mantel-Cox) test: ZH501 $\chi^{2}=4.362, d f=1, P=0.0367$; Lunyo $\chi^{2}=18.888, d f=1, P<0.0001$ ) (Fig. $2 \mathrm{~d}$ ) and in $C x$. pipiens (CBK) infected with strain $\mathrm{ZH} 501\left(\chi^{2}=6.607\right.$, $d f=1, P=0.0102$ ) (Fig. 2b) when compared to uninfected controls and lower dose counterparts. Mortality rates between virus doses in the Brookwood line were not statistically different (ZH501 $\chi^{2}=0.2687, d f=1$, $P=0.6042$; Lunyo $\chi^{2}=2.948, d f=1, P=0.0860$ ) (Fig. $2 \mathrm{c}$ ).

\section{Vector competence}

The mean titres of RVFV in the blood meal before and after feeding mosquitoes in the low dose group was $10^{6.0}$ and in the higher dose group was $10^{7.2} \mathrm{PFU} / \mathrm{ml}$, decreasing on average by 0.26 -logs during overnight feeding. Data for individual experimental groups are presented in Additional file 3: Figure S2. Reduction in virus titre in the mosquito compared to the blood meal indicated mosquitoes ingested between 1-10 $\mu \mathrm{l}$ of blood. Based on a measurement of GECs, levels of RVFV in engorged mosquitoes were similar irrespective of the mosquito species (Additional file 3: Figure S2).

The proportion of mosquitoes demonstrating infection, dissemination from the midgut, and a transmission potential for RVFV determined by qRT-PCR are shown in Fig. 3. Infectious viral particles determined by plaque assay were detected in the body and leg samples but not the saliva, with qRT-PCR results suggesting that viral titres in saliva were below the limit of detection of our plaque assay (Additional file 4: Table S1). The virus strain used had no significant effect on infection, dissemination or transmission rates in any of the mosquito species challenged with either RVFV strain; Ae. detritus (Fisher's exact test: bodies $P=1.0000$; legs $P=0.6870$; saliva $P=1.0000)$ and $C x$. pipiens (BKW) (Fisher's exact test: bodies $P=0.2910$; legs $P=0.1697$; saliva $P=1.0000)$.

Virus dose had the greatest impact on outcomes with all species showing an increase in infection, dissemination or transmission rate when mosquitoes were infected with the higher titre of virus. Due to low sample numbers, rates in Ae. rusticus were not compared. Rates of infection were significantly higher for all groups except $C x$. pipiens $(\mathrm{CBK})$ and dissemination for all except the $C x$. pipiens (BKW) infected with RVFV strain Lunyo. The transmission rates for mosquitoes infected with $10^{7} \mathrm{PFU}$ (or $10^{6}$ PFU reported in parentheses) were: $9 \%(0 \%)$ for $C x$. pipiens $(\mathrm{CBK})$ infected with strain $\mathrm{ZH} 501 ; 9$ and $7 \%(0 \%)$ for BKW infected with ZH501 and Lunyo; 18\% (3\%) and 23\% (0\%) for Ae. detritus strain ZH501 and Lunyo; and 0\% (0\%) for Ae. rusticus with ZH501. However, despite these observed increases, only the transmission rate by $A e$. detritus infected with strain Lunyo increased significantly at the higher dose (Fisher's exact test: $P=0.0115$ ). Only transmission rates between species Ae. detritus and $A e$. rusticus infected with $10^{7}$ PFU ZH501 differed significantly (Fisher's exact test: $P=0.0345$ ). 


\section{ZH501}

Lunyo
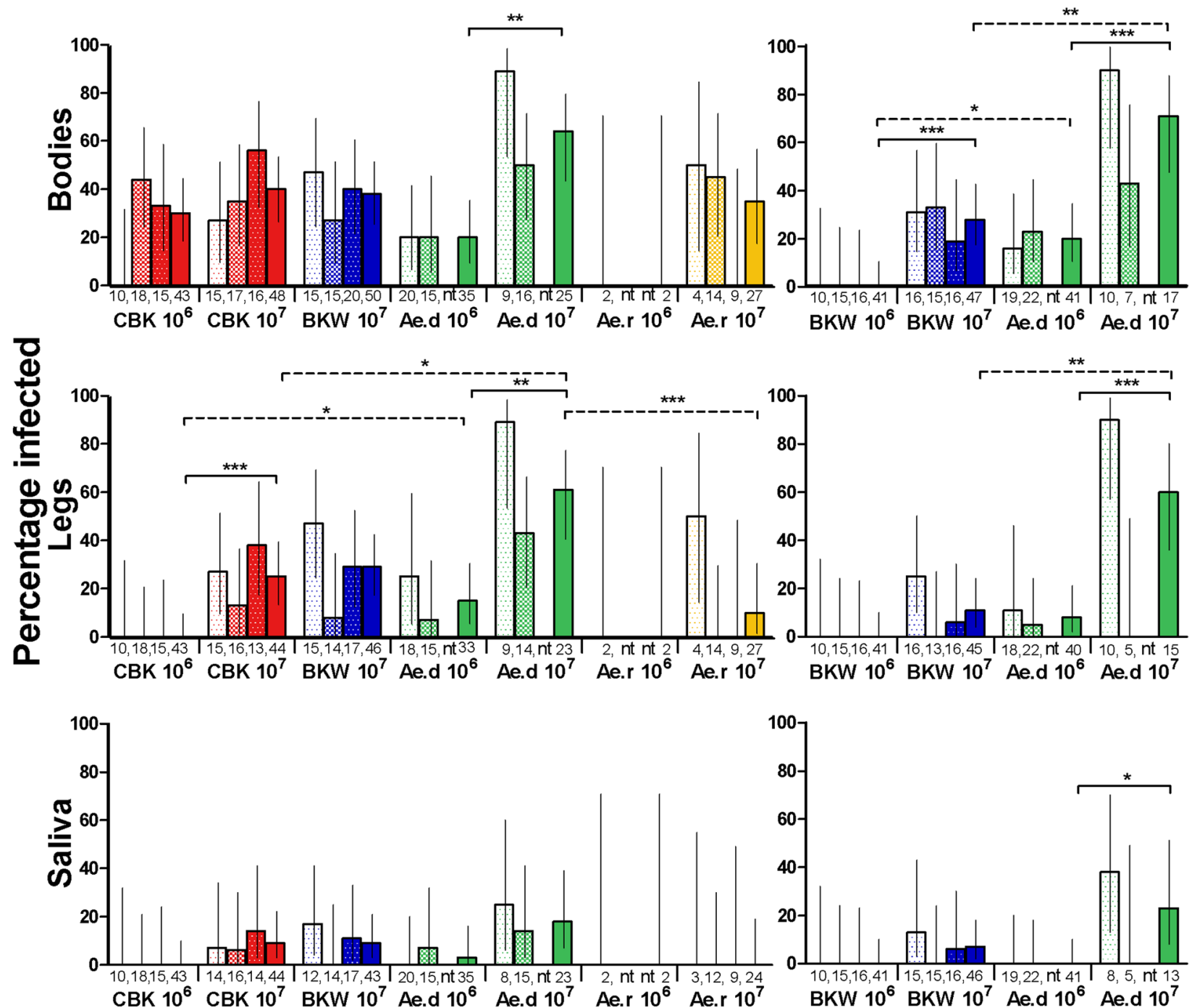

Day 7

Day 14

Day 21

All days

Fig. 3 Percentage of mosquitoes infected with Rift Valley fever virus. Mosquitoes were fed a blood-meal containing $10^{6}$ or $10^{7}$ PFU/ml Rift Valley fever virus strain Lunyo or ZH501 and maintained at 20 or $25^{\circ} \mathrm{C}$. Results are based on the proportion of mosquitoes positive for RVFV by qRT-PCR results. Day 0 was excluded from the totals. Numbers below bars represent the total number tested; error bars indicate $95 \%$ confidence intervals calculated by a modified Wald method. Fisher's exact test was used to compare between time points, doses and virus strains using a Bonferronicorrected threshold for multiple comparisons; comparisons between mosquito species are depicted by dotted bars, and comparison of doses by solid bars. Abbreviations: nt, not tested; CBK, Cx. pipiens (Caldbeck); BKW, Cx. pipiens (Brookwood); Ae.d, Ae. detritus; Ae.r, Ae. rusticus

Quantification of viral titres within different mosquito tissues can be used to indicate replication and evaluate the potential dose dependency of barriers encountered by the virus whilst progressing through the mosquito. The titres observed within mosquito bodies were fairly uniform across conditions and did not differ statistically between strains or the dose ingested (Mann-Whitney U-test: $P \geq 0.05$ ) (Additional file 4: Table S1). Temporal collection of honey-filters from groups of 10-15 mosquitoes corroborated the results of individual mosquito salivation, with RVFV RNA detected in the saliva of both $C x$. pipiens lines and Ae. detritus by day 7 postinfection, but not from Ae. rusticus. The average viral titres detected in the saliva were $10^{2.8}$ GEC ZH501 and $10^{3.6}$ GEC Lunyo and did not differ between mosquito species (strain ZH501 Kruskal-Wallis test: $H=1.196$, 
$P=0.5498$, strain Lunyo Mann-Whitney test: $U=2.00$, $P=0.4000)$ or collection method for $C x$. pipiens $(\mathrm{CBK})$ (Mann-Whitney test: strain ZH501 $U=17.00, P=0.2648$ ) , Cx. pipiens (BKW) (ZH501 $U=4.00, P=0.3429$; Lunyo $U=13.00, P=1.0000)$ or Ae. detritus (ZH501 $U=26.00$, $P=0.1580$; Lunyo $U=16.00, P=0.8286$ ) (Additional file 4: Table S1).

In addition to competence experiments performed with wild-caught Ae. detritus and Ae. rusticus, further wild-caught species were investigated (Table 1). Aedes cantans/annulipes collected from woodlands were not susceptible to infection; however, the sample size was small $(n=7)$. Culex pipiens were collected from three locations in southern England but failed to feed using an artificial feeding device. Culex modestus and Ae. caspius were collected from sites with mixed populations. Although sample numbers were low, at $10 \mathrm{dpi}$ a single $C x$. modestus had disseminated virus (1 of 5 ) and a single Ae. caspius had RVFV RNA in the saliva (1 of 6).

\section{Discussion}

This study assessed British populations of mosquitoes for their ability to support and transmit RVFV. Under laboratory conditions, two lines of $C x$. pipiens and Ae. detritus demonstrated the potential to transmit RVFV, with the detection of low levels of viral RNA in expectorated saliva. There were no differences in the rates of mortality, infection, dissemination or transmission between strains ZH501 or Lunyo but mosquito survival was negatively affected by high viral dose $\left(10^{7} \mathrm{PFU}\right)$ and at the higher temperature $\left(25^{\circ} \mathrm{C}\right)$.

Ingested viral dose had a significant effect on the infection, dissemination and transmission rates, concurring with previous studies $[28,39,40]$. Natural peak viraemia in calves and lambs range between $10^{6}-10^{8} \mathrm{PFU} / \mathrm{ml}[27,28]$. Two doses at the low $\left(10^{6} \mathrm{PFU}\right)$ and medium $\left(10^{7} \mathrm{PFU}\right)$ range of this viraemia were evaluated to determine the lower threshold required to artificially infect mosquitoes. Neither of the $C x$. pipiens lines were able to support dissemination of virus from the midgut at the lower dose and therefore could not transmit RVFV. At this lower dose the $C x$. pipiens Caldbeck line, supported replication but the Brookwood line did not, suggesting the presence of a barrier to escape from and infection of the midgut, respectively in these mosquito lines. Multiple mechanisms have been postulated, including physical barriers to virus or incompatibility with host receptors or antiviral responses including RNA interference and degradation by midgut enzymes [41]. Further work is required to understand the mechanisms involved for these species, for example using microscopy to evaluate virus localisation. However, Ae. detritus, once infected with RVFV, supported high proportions of disseminated infection at the lower dose and virus was detected in saliva of a single mosquito demonstrating that this species has the potential to transmit RVFV.

Combining the collection points at the low dose we analysed 43 (ZH501) Cx. pipiens (CBK), 41 (Lunyo) Cx. pipiens (BKW) and 35 (ZH501) and 36 (Lunyo) Ae. detritus. Assuming less than $10 \%$ of mosquitoes within a population can transmit, the number of test specimens required to detect at least one positive with 95\% confidence is 29 mosquitoes (herd sensitivity model, assuming infinite population size [37]). Although greater numbers would increase the statistical power, these data support this inability to transmit virus where results were negative, based on the numbers evaluated.

Transmission increased in all species at the medium dose of $10^{7}$ PFU, except Ae. rusticus which demonstrated limited capability to disseminate at later time points; however, the low sample numbers $(n=20)$ for this species limit the strength of this observation. At this dose the barriers to infection were generally overcome in both Culex lines; virus infected a moderate number and escaped the midgut of a large proportion of infected specimens. Aedes detritus had high infection and dissemination rates but the mosquitoes did not differ in their transmission rates compared to Culex, suggestive of potential salivary gland barriers as observed previously by Gargan et al. [42]. Further work is needed to confirm this hypothesis, and the methods used cannot differentiate between an infection or escape barrier; dissecting the salivary glands and detailed microscopy could increase our understanding of the underlying mechanisms [41].

Viral titres in the saliva did not differ as a result of mosquito species, infectious dose or RVFV strain (Additional file 4: Table S1). Assessing the potential to transmit based on levels of RVFV RNA in saliva, suggests that there is an equal capability between species to pass virus horizontally to vertebrates, although this observation is limited by the low number of mosquitoes expectorating virus. Failure to detect infectious virus in the saliva is likely a limitation of the plaque assay technique. Diluting the samples to screen by sensitive molecular methods increased throughput but introduced a freeze-thaw potentiating virus degradation. Although the detection of viral RNA in saliva demonstrates a potential for transmission, it is not known if the titres detected here are sufficient to cause disease. Previous reports have suggested that in vitro collection of saliva underestimates titres and local inflammatory responses in the vertebrate may facilitate viral infection $[43,44]$. Therefore, important next steps are demonstrating this ability to transmit functional virions to an animal model resulting in disease, to confirm transmission.

The dose dependence observed limits the period that feeding mosquitoes could support transmission in the field, to the short duration of the peak viraemia (Fig. 1a) as reported previously [44]. This peak viraemia typically occurs 
on day three post-infection in young ruminants and lasts for less than $24 \mathrm{~h}$. Based on data presented using artificial blood meals, mosquitoes feeding outside of this window would not transmit RVFV, although previous observations suggest infection and transmission rates may be underestimated and dose threshold overestimated by the use of artificial blood meals compared to feeding on a viraemic hamster or lamb $[44,45]$. It is feasible, therefore, that these differences in experimental design account for the lower rate of transmission observed in $C x$. pipiens derived from the UK compared to the Netherlands [44] rather than genetic differences between different populations of the same species [15].

The temporal interplay between peak viraemia of the vertebrate host and progression of virus to the saliva of the vector host are important, fundamentally supporting or prohibiting transmission (Fig. 1). The extrinsic incubation period for transmitting mosquitoes was $\leq 7$ days post-infection, however earlier time points were not tested. Although the durations between seeking blood meals are unknown for these species, the ability to transmit within just 7 days of ingestion of viruses increases the transmission potential in subsequent feeds (Fig. 1b, scenarios 1 and 3). Survival of the virus, and ultimately transmission, is reliant on vector host survival. Differences in mosquito mortality rates are likely to have the greatest impact on the capacity to transmit virus in the field (Fig. 1b, scenario 3). High mosquito mortality was observed at $25{ }^{\circ} \mathrm{C}$ compared to $20{ }^{\circ} \mathrm{C}$ in field-caught Aedes species; the concurrent mortality of controls and infected mosquitoes suggests a virus-independent factor. It is conceivable that both Aedes populations have adapted to cooler (temperate) climates in their coastal and woodland habitats. The high mortality observed at $25{ }^{\circ} \mathrm{C}$, limited the ability to directly compare vector competence at two temperatures applied to the wildcaught species in this study. Although temperature increases are typically observed to increase vector competence, similar findings of an inverse relationship with temperature and vector capacity have been observed previously with increased mortality limiting transmission [46]. However, the effect of natural diurnal temperature fluctuations should also be considered [46] and the lower thermal limit at which RVFV transmission can occur determined.

Increased mortality in $C x$. pipiens Caldbeck and Ae. detritus infected with the higher viral dose was also observed, consistent with previous reports [47]. This virusdependent factor occurred exclusively in infected (not control) groups. Despite high disseminated titres in the hybrid, survival did not differ significantly between dose groups, thereby increasing its capacity as a vector. Tissue damage and resource depletion as a result of rapid viral amplification have been postulated as causes of cytopathic effects observed in flavivirus-infected mosquitoes [48]. Further studies comparing the high and low mortality groups observed could advance our understanding of mechanisms affecting survival.

Multiple factors including changes in land-use and climate predict increases in mosquito species and numbers within Europe, thereby increasing the risk of arbovirus emergence and establishment [49]. Despite the limitation of studying mosquitoes under experimental conditions, this approach offers important data for identifying temperate mosquitoes present in the UK as potential vectors of RVFV.

\section{Conclusions}

The spread of RVFV to Europe and its establishment would severely impact the health of humans, livestock and the economy. To assess the risk of establishment, an understanding of the ability of indigenous mosquitoes to support and transmit RVFV is required. However, vector competence remains one element of vector capacity so it is important to pair these data with behavioural and lifehistory traits in the field, such as host-feeding preference, time between feeding events and survival. We report the ability of laboratory colonised populations of Cx. pipiens and wild-caught Ae. detritus from the UK to transmit RVFV RNA in their saliva. These data suggest that comparable wild mosquito species surviving under parallel environmental conditions might also have the ability to transmit RVFV. In these natural habitats and based on the feeding preferences of Ae. detritus, it can be further speculated that under the right circumstances these temperate mosquito species, that are competent for RVFV, may be able to infect susceptible livestock and pose a threat to public health.

\section{Additional files}

Additional file 1: Figure S1. Map of mosquito collection site locations. Map generated using ArcMap version 10.4. (TIF 70791 kb)

Additional file 2: Methods S1. Supplementary methods: endogenous PCR control for mosquito saliva samples. (DOCX $27 \mathrm{~kb}$ )

Additional file 3: Figure S2. Viral titres within the blood meal and ingested by mosquitoes. Dots represent median RVFV titres per $\mathrm{ml}$ of blood, quantified before and after feeding. Boxes represent the RVFV titres ingested by mosquitoes, horizontal lines at the median and whiskers showing minimum and maximum values. Samples were stored at $-80^{\circ} \mathrm{C}$. Genome equivalent copies (GEC) and infectious virus titres (PFU) were calculated by qRT-PCR and plaque assay. Abbreviations: CBK, Cx. pipiens (Caldbeck colony); BKW, Cx. pipiens (Brookwood colony); Ae.d, Ae. detritus; Ae.r, Ae. rusticus. Statistical comparison of ingested dose (GEC) was performed by Mann-Whitney U-test in GraphPad prism: Lunyo CX. pipiens Brookwood vs Ae. detritus $10^{6}$ dose cohort: $U=18.00,=0.171 ; 10^{7}$ cohort: $U=28.00, P=0.1040 ; Z H 501$ dose $10^{6} \mathrm{Cx}$. pipiens Caldbeck vs Ae. detritus: $U=86, P=0.5524$; and all four mosquito populations infected with ZH501 at $10^{7}$ Kruskal-Wallis test: $\left.H=0.5458, P=0.9087\right)$. Demonstrating uniformity between the experimental groups and mosquito species. (TIF $190 \mathrm{~kb}$ )

Additional file 4: Table S1. Viral RNA and infectious viral titres within the bodies, legs and saliva of UK mosquitoes infected with RVFV. Mosquitoes were fed a blood meal containing $10^{6}$ or $10^{7} \mathrm{PFU} / \mathrm{ml}$ RVFV strain Lunyo or ZH501 and maintained at 20 or $25^{\circ} \mathrm{C}$. Results are based on the mean $\log _{10^{-}}$ transformed qRT-PCR results reported in genome equivalent copies (GEC) 
and plaque assay results reported in plaque forming units (PFU). Day 0 was excluded from the totals. Abbreviations: nt, not tested; $n$, number tested; dpi, day post-infection. Dose range based on infectious titres obtained in pre and post feed blood samples. (XLSX $18 \mathrm{~kb})$

\section{Acknowledgements}

We thank the Pirbright Institute, UK for providing the Cx. pipiens colonies: and Dr Gail Chapman, Dr Marcus Blagrove and Kenneth Sherlock, University of Liverpool, Institute of Infection and Global Health, UK, Dr Ben Cull and Alexander Vaux, Medical Entomology and Zoonoses Ecology Group, PHE, UK for their support in mosquito collection.

\section{Funding}

This work was funded by the University of Surrey, Public Health England (PHE) and the Animal and Plant Health Agency (APHA) through grant SC1402 and supported by the Department for Environment, Food and Rural Affairs and the Scottish and Welsh governments through grants SV3045 and SE4113. The views expressed are those of the authors not necessarily those of the funding bodies.

\section{Availability of data and materials}

The data supporting the conclusions of this study are included within the article and its additional files.

\section{Authors' contributions}

All authors were involved with experimental design. SL, NJ, LMHT and MF performed competence experiments. SL wrote the first draft of this manuscript, performed all virological assays and analysed these data. All authors read and approved the final manuscript.

\section{Ethics approval and consent to participate}

Not applicable.

\section{Competing interests}

The authors declare that they have no competing interests.

\section{Publisher's Note}

Springer Nature remains neutral with regard to jurisdictional claims in published maps and institutional affiliations.

\section{Author details}

${ }^{1}$ Microbiology Services Division, Public Health England, Wiltshire, UK. ${ }^{2}$ School of Veterinary Medicine, University of Surrey, Guildford, UK. ${ }^{3}$ Wildlife Zoonoses and Vector-borne Diseases Research Group, Animal and Plant Health Agency, Addlestone, Surrey, UK. ${ }^{4}$ NIHR Health Protection Research Unit in Emerging and Zoonotic Infections, University of Liverpool, Liverpool, UK. ${ }^{5}$ Department of Clinical Infection, Microbiology and Immunology, University of Liverpool, Liverpool, UK.

\section{Received: 12 February 2018 Accepted: 2 May 2018}

Published online: 18 May 2018

\section{References}

1. Daubney R, Hudson JR, Garnham PC. Enzootic hepatitis or Rift Valley fever. An undescribed virus disease of sheep cattle and man from East Africa. J Pathol. 1931;34:545-79.

2. Hoogstraal H, Meegan JM, Khalil GM, Adham FK. The Rift Valley fever epizootic in Egypt 1977-78. 2. Ecological and entomological studies. Trans R Soc Trop Med Hyg. 1979;73:624-9.

3. Jupp PG, Kemp A, Grobbelaar A, Leman P, Burt FJ, Alahmed AM, et al. The 2000 epidemic of Rift Valley fever in Saudi Arabia: mosquito vector studies. Med Vet Entomol. 2002;16:245-52.

4. Gür S, Kale M, Erol N, Yapici O, Mamak N, Yavru S. The first serological evidence for Rift Valley fever infection in the camel, goitered gazelle and Anatolian water buffaloes in Turkey. Trop Anim Health Prod. 2017:49:1531-5.

5. Lumley S, Horton DL, Hernandez-Triana LM, Johnson N, Fooks AR, Hewson R. Rift Valley fever virus: strategies for maintenance, survival and vertical transmission in mosquitoes. J Gen Virol. 2017;98:875-87.

6. Chevalier V, Pépin M, Plée L, Lancelot R. Rift Valley fever - a threat for Europe? Euro Surveill. 2010;15:19506.
7. Linthicum KJ, Davies FG, Kairo A, Bailey CL. Rift Valley fever virus (family Bunyaviridae, genus Phlebovirus). Isolations from Diptera collected during an inter-epizootic period in Kenya. J Hyg (Lond). 1985;95:197-209.

8. Manore CA, Beechler BR. Inter-epidemic and between-season persistence of Rift Valley fever: vertical transmission or cryptic cycling? Transbound Emerg Dis. 2015;62:13-23.

9. Davies FG, Linthicum KJ, James AD. Rainfall and epizootic Rift Valley fever. Bull World Health Organ. 1985;63:941-3.

10. Meegan JM. The Rift Valley fever epizootic in Egypt 1977-78. 1. Description of the epizootic and virological studies. Trans R Soc Trop Med Hyg. 1979;73:618-23.

11. Fonseca DM, Keyghobadi N, Malcolm CA, Mehmet C, Schaffner F, Mogi M, et al. Emerging vectors in the Culex pipiens complex. Science. 2004;303:1535-8.

12. Farajollahi A, Fonseca DM, Kramer LD, Marm KA. "Bird biting" mosquitoes and human disease: a review of the role of Culex pipiens complex mosquitoes in epidemiology. Infect Genet Evol. 2011;11:1577-85.

13. Vogels CBF, Fros JJ, Göertz GP, Pijlman GP, Koenraadt CJM. Vector competence of northern European Culex pipiens biotypes and hybrids for West Nile virus is differentially affected by temperature. Parasit Vectors. 2016;9:393.

14. Brustolin M, Talavera S, Nuñez A, Santamaría C, Rivas R, Pujol N, et al. Rift Valley fever virus and European mosquitoes: vector competence of Culex pipiens and Stegomyia albopicta (=Aedes albopictus). Med Vet Entomol. 2017;31:365-72.

15. Turell MJ, Dohm DJ, Fonseca DM. Comparison of the potential for different genetic forms in the Culex pipiens complex in North America to transmit Rift Valley fever virus. J Am Mosq Control Assoc. 2014;30:253-9.

16. Harbach RE, Dallimore T, Briscoe AG, Culverwell CL, Vaux AGC, Medlock JM. Aedes nigrinus (Eckstein, 1918) (Diptera, Culicidae), a new country record for England, contrasted with Aedes sticticus (Meigen, 1838). ZooKeys. 2017;671:119-30.

17. Snow KR, Rees AT, Bulbeck SJ. A provisional atlas of the mosquitoes of Britain. London: University of East London; 1998

18. Medlock JM, Snow KR, Leach S. Possible ecology and epidemiology of medically important mosquito-borne arboviruses in Great Britain. Epidemiol Infect. 2007:135:466-82.

19. Cranston PS, Ramsdale CD, Snow KR, White GB. Adults, larvae, and pupae of British mosquitoes (Culicidae): A Key. Ambleside, Cumbria: Freshwater Biological Association; 1987.

20. Snow KR, Terzi AJE. Mosquitoes. Slough: Richmond; 1990

21. Hebert PDN, Cywinska A, Ball SL, de Waard JR. Biological identifications through DNA barcodes. Proc R Soc B. 2003:270:313-21.

22. Manley R, Harrup LE, Veronesi E, Stubbins F, Stoner J, Gubbins S, et al. Testing of UK populations of Culex pipiens L. for Schmallenberg virus vector competence and their colonization. PLoS One. 2015;10:e0134453.

23. Lumley S, Horton DL, Marston DA, Johnson N, Ellis RJ, Fooks AR, et al. Complete genome sequence of Rift Valley fever virus strain Lunyo. Genome Announc. 2016;4:e00170-16.

24. Weinbren MP, Williams MC, Haddow AJ. A variant of Rift Valley fever virus. S Afr Med J. 1957;31:951-7.

25. Bird BH, Khristova ML, Rollin PE, Ksiazek TG, Nichol ST. Complete genome analysis of 33 ecologically and biologically diverse Rift Valley fever virus strains reveals widespread virus movement and low genetic diversity due to recent common ancestry. J Virol. 2007;81:2805-16.

26. Richard V, Viallon J, Cao-Lormeau V-M. Use of centrifugal filter devices to concentrate dengue virus in mosquito per os infection experiments. PLoS One. 2015:10:e0138161.

27. Bird BH, Ksiazek TG, Nichol ST, MacLachlan NJ. Rift Valley fever virus. J Am Vet Med Assoc. 2009;234:883-93.

28. Golnar AJ, Turell MJ, LaBeaud AD, Kading RC, Hamer GL. Predicting the mosquito species and vertebrate species involved in the theoretica transmission of Rift Valley fever virus in the United States. PLoS Negl Trop Dis. 2014;8:e3163.

29. EFSA. The risk of a Rift Valley fever incursion and its persistence within the community. EFSA J. 2005;3:1-128.

30. Aitken THG. An in vitro feeding technique for artificially demonstrating virus transmission by mosquitoes. Mosquito News. 1977;37:130-3.

31. Beckmann JF, Fallon AM. Decapitation improves detection of Wolbachia pipientis (Rickettsiales: Anaplasmataceae) in Culex pipiens (Diptera: Culicidae) mosquitoes by the polymerase chain reaction. J Med Entomol, 2012:49:1103-8.

32. Weidmann M, Sanchez-Seco MP, Sall AA, Ly PO, Thiongane Y, Lô MM, et al. Rapid detection of important human pathogenic phlebovirus. J Clin Virol. 2008;41:138-42. 
33. Drosten C, Göttig S, Schilling S, Asper M, Panning M, Schmitz H, et al. Rapid detection and quantification of RNA of Ebola and Marburg viruses, Lassa virus, Crimean-Congo hemorrhagic fever virus, Rift Valley fever virus, dengue virus, and yellow fever virus by real-time reverse transcription-PCR. J Clin Microbiol. 2002;40:2323-30.

34. Staley M, Dorman KS, Bartholomay LC, Fernández-Salas I, Farfan-Ale JA, Loroño-Pino MA, et al. Universal primers for the amplification and sequence analysis of actin-1 from diverse mosquito species. J Am Mosq Control Assoc. 2010;26:214-8

35. Grubaugh ND, Fauver JR, Rückert C, Weger-Lucarelli J, Garcia-Luna S, Murrieta RA, et al. Mosquitoes transmit unique West Nile virus populations during each feeding episode. Cell Reports. 2017;19:709-18.

36. Met Office. UK climate. 2012. http://www.metoffice.gov.uk/public/weather/ climate. Accessed 12 Sep 2015.

37. DiGiacomo RF, Koepsell TD. Sampling for detection of infection or disease in animal populations. J Am Vet Med Assoc. 1986;189:22-3.

38. Agresti A, Coull BA. Approximate is better than "exact" for interval estimation of binomial proportions. Am Stat. 1998;52:119-26.

39. Turell MJ, Faran ME, Cornet M, Bailey CL. Vector competence of Senegalese Aedes fowleri (Diptera: Culicidae) for Rift Valley fever virus. J Med Entomol. 1988;25:262-6.

40. Chamberlain RW, Sudia WD. Mechanism of transmission of viruses by mosquitoes. Ann Rev Entomol. 1961;6:371-90.

41. Hardy JL, Houk EJ, Kramer LD, Reeves WC. Intrinsic factors affecting vector competence of mosquitoes for arboviruses. Ann Rev Entomol. 1983;28:229-62.

42. Gargan TP, Bailey CL, Higbee GA, Gad A, El Said S. The effect of laboratory colonization on the vector-pathogen interactions of Egyptian Culex pipiens and Rift Valley fever virus. Am J Trop Med Hyg. 1983;32:1154-63.

43. Styer LM, Kent KA, Albright RG, Bennett CJ, Kramer LD, Bernard KA. Mosquitoes inoculate high doses of West Nile virus as they probe and feed on live hosts. PLoS Pathog. 2007;3:1262-70.

44. Vloet RPM, Vogels CBF, Koenraadt CJM, Pijlman GP, Eiden M, Gonzales JL, et al. Transmission of Rift Valley fever virus from European-breed lambs to Culex pipiens mosquitoes. PLoS Negl Trop Dis. 2017;11:e0006145.

45. Turell MJ. Reduced Rift Valley fever virus infection rates in mosquitoes associated with pledget feedings. Am J Trop Med Hyg. 1988;39:597-602.

46. Lambrechts L, Paaijmans KP, Fansiri T, Carrington LB, Kramer LD, Thomas $M B$, et al. Impact of daily temperature fluctuations on dengue virus transmission by Aedes aegypti. Proc Natl Acad Sci USA. 2011:108:7460-5.

47. Faran ME, Turell MJ, Romoser WS, Routier RG, Gibbs PH, Cannon TL, et al. Reduced survival of adult Culex pipiens infected with Rift Valley fever virus. Am J Trop Med Hyg. 1987;37:403-9.

48. Girard YA, Popov V, Wen J, Han V, Higgs S. Ultrastructural study of West Nile virus pathogenesis in Culex pipiens quinquefasciatus (Diptera: Culicidae). J Med Entomol. 2005;42:429-44.

49. Medlock JM, Vaux AGC. Impacts of the creation, expansion and management of English wetlands on mosquito presence and abundance - developing strategies for future disease mitigation. Parasit Vectors. 2015:8:142.

50. Walton WE. Protocol for mosquito sampling for mosquito best management practices on State of California - managed wildlife areas. Sacramento: University of California; 2005.

51. Versteirt V, Nagy ZT, Roelants P, Denis L, Breman FC, Damiens D, et al. Identification of Belgian mosquito species (Diptera: Culicidae) by DNA barcoding. Mol Ecol Resour. 2015;15:449-57.

52. Golding N, Nunn MA, Medlock JM, Purse BV, Vaux AG, Schäfer SM. West Nile virus vector Culex modestus established in southern England. Parasit Vectors. 2012;5:32.

53. Mackenzie-Impoinvil L, Impoinvil DE, Galbraith SE, Dillon RJ, Ranson $H_{\text {, }}$ Johnson N, et al. Evaluation of a temperate climate mosquito, Ochlerotatus detritus (= Aedes detritus), as a potential vector of Japanese encephalitis virus. Med Vet Entomol. 2015:29:1-9.

54. Medlock JM, Vaux AG. Colonization of UK coastal realignment sites by mosquitoes: implications for design, management, and public health. J Vector Ecol. 2013;38:53-62.

\section{Ready to submit your research? Choose BMC and benefit from:}

- fast, convenient online submission

- thorough peer review by experienced researchers in your field

- rapid publication on acceptance

- support for research data, including large and complex data types

- gold Open Access which fosters wider collaboration and increased citations

- maximum visibility for your research: over $100 \mathrm{M}$ website views per year

At BMC, research is always in progress.

Learn more biomedcentral.com/submissions 